\title{
Plato's Usage of phone in Protagoras
}

Mostafa Younesie

Phone is a topic that is not so much explored and examined in Plato. Given eighteen times use of this word in Protagoras, this dialogue can be the suitable place to do a research about its meanings. Here the use of phone covers different subjects and facets of this word as an umbrella word so that in order to reach an ordered and meaningful understanding we place those aspects which are analogous in specific set and title.

\section{Introduction}

When scholars want to speak about Plato's speculation on phone ( $\varphi \omega v \eta$ ) they speak in short or by hesitation. Apart from the reasons for such positions, with regard to Plato's various short or relatively long reflections on phone in different dialogues and the importance of such a discussion for ancient Greek grammar, here I want to classify his multiple and scattered thoughts into multiple meaningful organic constructs with reference to Protagoras. Such an endeavor can function as a preclude for other aspects of this concept in other Plato's dialogues too.

Of course, on the first view it may seem that Protagoras is not a suitable text for such a concern, but when we encounter there eighteen times the word phone in multiple and different guises, it shows that there can be something about this word which may be reached by rereading.

In this respect, first I will present the eighteen cases in the form of sentences as the meaningful unit, and then I describe each one in order to shape overall and particular images. At the beginning and the end of this dialogue, the word phone is at the minimal use, but in the middle, it is of its maximum and is related with issues such as Simonides poem; the distinction between symposiums of the uncultured many from the special 
cultured few; and the Platonic Protagoras' mythical / logos narratives. Moreover, it is noteworthy that I use the translation by Adam Beresford 2005 that as far as possible he tries to bring and write the different means of phone is their appropriate places. But first I use the transliterated form of the original Greek word.

310b- At the beginning of the main dialogue two times and near each other the word phone is used.

1- Last night, a little bit before dawn, my friend Hippocrates - started making a huge racket banging (...), he came charging straight in and said, in a loud phone, Socrates! Are you awake, or asleep?

2- I recognized his phone and said (...).

315b- Here phone is repeated near each other for two times:

1- (...) the people Protagoras gathers from the cities he passes through: he draws them with his spellbinding phone, like Orpheus,

2- and wherever the phone leads, they follow, under his spell.

316a- He [Prodicus] is a brilliant man, in my view, truly inspired - the problem was he's got such a deep phone that it set off a kind of rumbling echo inside the room, and I could not make out a word.

322a- and as well as that, by using their ingenuity, they soon come up with words for things and formed articulate phone and invented shelters, (....).

$325 \mathrm{e}-$ So the teachers make care of all that, and once the boys learn the alphabet and are just starting to understand written texts, just like when they started to understand spoken phone, the teachers set out beside them, ...

332c- And is there such a thing, in phone, as high [pitch]? And that does not have any opposite besides low [pitch], does it?

341b- I know- let's ask Prodicus. After all, he's the right person to ask about Simonides' phone, isn't he?

341c- He's clearly reprimanding Pittacus for not knowing how to make accurate semantic distinctions, because he is from Lesbos and was brought up speaking some barbarous phone.

346d- (notice how here he's gone into Mytilenian phone - "I gonna give my praise"- that's because he's speaking directly to Pittacus)

$347 \mathrm{c}-(\ldots)$ they [market people] are not capable of entertaining each other over drinks just with their own company, with the phone of their own voices and their own ideas - because of their lack of sophistication $-(\ldots)$.

$347 \mathrm{~d}-(. .$.$) so they drive up the price of flute-girls by paying out a lot of money to get a phone in$ from somewhere else - of the flute - and then rely on that phone for entertaining each other.

- But at parties where decent, classy people are drinking together, educated people, ..., relying on the phone of their own voices, taking turns to speak and to listen to one another in an orderly fashion (...).

$347 \mathrm{e}-(\ldots)$ as long as the people taking part are the sort of people most of us claim to be, then they should not need any outside phone, not even of the poets and songwriters $<\ldots>$.

$356 \mathrm{c}$ - and do not phone of equal volume seem louder from up close and fainter from far away?

361a- (...) and if our Ending could have phone, she'd be saying, Protagoras and Socrates! You two Guys are so silly! 
After representing the body of evidences about uses of the word phone, as far as possible we try to figure out their different and suitable meanings and put them in various sets with specific titles.

\section{Features of phone}

At the beginning of the main dialogue which Socrates narrates (310b), we are confronted with an Athenian man in special mood who at an untimely hour shows up at Socrates home knocking the door. Therefore, his voice itself has an emotional color and wants to communicate some feelings and then addresses Socrates by loud voice:

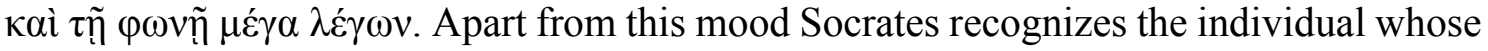
voice he hears. For it is a facet of voice of the person named Hippocrates whose original and usual voice he knows.

According to this image, it seems that phone is a mood-fused voice that originates within human being. When it comes out the other human beings can hear and have some conceptions of it. In other words, each human being has his or her special voice that shapes his or her voice identity in distinction from the other human beings, but at the same time different factors can influence and give it circumstantial and situational facets. Thus, there is the voice of normal / situational Hippocrates.

We can visualize this emotional milieu, Hippocrates as a Greek man who is interested in and seeks to become the student of Protagoras whose news of coming to the city makes him so excited and happy to go to Socrates and calls him loudly in order to get up and accompany him to Protagoras. Thus, his voice has not merely an empirical feature but emotional and psychological, too.

At the same time, the use of adjective loud for human voice proposes another feature of phone that is very crucial. Since later on Plato uses two other features of phone, it is very important that on the basis of a criterion we make a distinction, then translate the adjectives of phone. The criterion is the implicit distinction between "volume" and "pitch" of phone that Plato draws by using specific adjectives. Here by using "loud" he

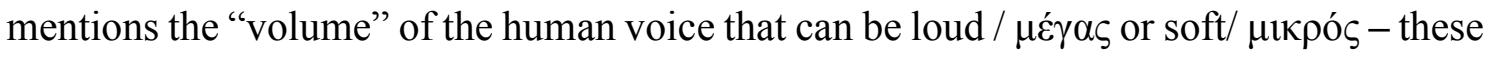
vocal equivalents have transferred / metaphorical background in big and small size (my reference for the Greek text is W.R.M. Lamb 1924). This feature of sound with its counterpart comes near the end of dialogue and denotes the fact that from near or far we

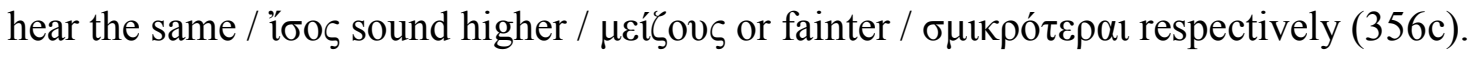


But it is not all, for Plato introduces the "pitch" of sound too in binary forms of

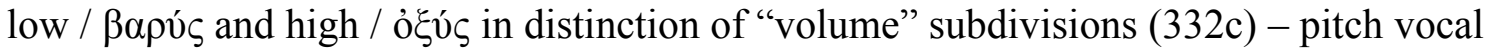
equivalents have transferred / metaphorical background in space (Andrew Barker 2002, 24 n.4, 26 n.8). As an example of this distinct feature, we can refer to the low - deep pitch voice of Prodicus (3161) who is an expertise in word distinctions and meanings. At the same time, there is an irony for the teacher of letters and distinctions who speaks in a lowdeep voice, in a closed room, with too many students which make impossible for Socrates to hear clearly and properly what he says and teaches.

The last but not the least, there is another quality of phone that is mentioned in regard to Protagoras. When Socrates and Hippocrates go to Callias' home as a new environment with specific characteristics, we face other facets of phone whose meanings should be figured out. Interestingly, here the word phone is used sixteen times all in relation to human beings except one.

In this new spatial/phonic milieu, the first voice that Socrates narrates is related to Protagoras (315a-315b) who as a foreigner (not from Athens) and traveling teacher has a magic voice by enchanting and absorbing his listeners $\kappa \eta \lambda \tilde{\omega} v \underline{\tau \tilde{\eta}} \varphi \omega v \tilde{\eta}$. This quality of Protagoras voice, apart from the content, makes it similar to Orpheus but different from Hippocrates and it is a kind of voice that comes out of a specific human being and when the listeners hear it a special ecstatic state affects them $\underline{\kappa \eta \lambda \tilde{\omega} v}$.

Accordingly, this kind of voice has the power of leading and moving its listeners in specific forms. Thus, some individuals and not all can have such a magic voice that is qualitative and perhaps reason cannot completely explain it especially when Socrates compares it with the voice of Orpheus who is a complex and ambiguous mystic.

Therefore, under the features of sound we considered and put those parts of dialogue which pertain to the characteristics of human being or non-human being sound. Accordingly, sound can have three distinct vocal and emotional features: high / low (the sound of Prodicus) pitch; loud (the sound of Hippocrates) / soft volume; and enchanting. These are distinct features of phone that have their origin in non-vocal fields of weight, size and magic and are appropriated for the vocal field. Thus, here the issue is not the nature, definition or cause of sound but its characteristics. 
Platonic Protagoras on phone

Protagoras as the possessor of a magical voice gives some clues and points about voice and logos that are significant and noteworthy. In other words, we read in a nutshell idea of Platonic Protagoras (322a-325e) about voice, and here is one of the turning points in a dialogue that is named after this individual who introduces and mentions the crucial "stages" of voice. At the initial phase in the context of myth, he introduces the ordered

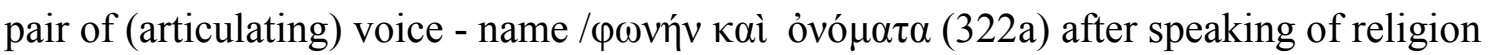
and building. In relation to the above-mentioned pair, I want to suggest that in the texture of myth it seems that the men pronounce out of instinct and unconsciously sounds that at first they do not know their rationales and justifications. But gradually human beings become conscious and informed by thinking about these sounds and then distinguish and delineate them from each other according to specific justifications. All these are the first steps for articulating and joining these sounds in order to make words that have meaningful relations with things - being natural or conventional is not mentioned. In classical Greek, onoma has many meanings and extensions and is not limited merely and only to noun or name but with regard to Greek linguistic context "name" is more suitable and historical (Gera 2003, 135). Accordingly, we suggest that the common thread of all these meanings and extensions return to "naming something" as an advanced cognitive phase. In other words, although at first it is unconscious, the pronounced sounds denote the things in the world and later on human beings acquire skills in order to make meaningful and justifiable their doings. This new event is very basic. Interestingly, in this regard the Platonic Protagoras does mention to the necessity of specific expertise and

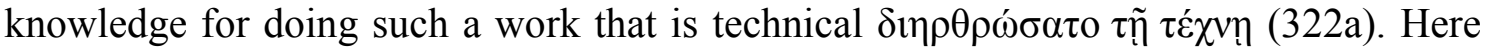
we have two key words that should be mentioned.

The first Greek word $\delta i \eta \rho \rho \omega ́ \sigma \alpha \tau o$ means to make meaningful relations among distinct voices and this task should be done with skill that is equivalent for the second word $\tau \varepsilon \dot{\chi} \chi \eta\rceil$. Therefore, in Platonic Protagoras men should be equipped with the special pertinent skill in order to make relations between the voices that are separate and distinct from each other. Thus, the skilled individuals make links between separate voices and this linkage comes after a separation. For being distinguished or separate is not sufficient, we should come out from this condition and doing so is possible by a specific kind of skill that enables us to make meaningful connections. Moreover, this technical endeavor has to have relation with its pertinent things for we do not make name for itself. According 
to the wordings of Plato, these two phases are distinct but dependent on each other: "sound / name". We pronounce the "sounds" before shaping them in the form of "word" which in meaningful relation "name" their pertinent subject.

Afterwards, this oral aspect of phone or voice is made salient by pairing it with

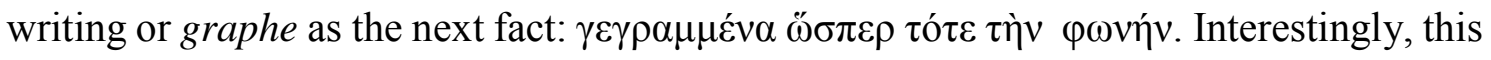
aspect is introduced in the context of Protagoras' narration of logos (325e), perhaps mythos does not need writing!

In this context, the emergence of schools denotes the forming of alphabet and writing, therefore students come to school in order to learn how to write and read since they know how to talk their mother language. It seems that for Protagoras the origin of writing returns to speaking. Besides, students come to school in order to learn correctly and consciously both speaking and writing in a formal place from those who are called teachers and have the necessary skills for teaching these two subjects. If we put these two pairs together, we see a chain with this linear order: voice - name/ word - speaking writing. According to the context it is justifiable to say that at the first sentence (322a) phone is equivalent to "voice" but at the second sentence $(325 \mathrm{e})$ it is equivalent to "speaking".

\section{Phone as Dialect and Colloquy}

After reading short basic points of Platonic Protagoras about sound, now we reach to a place in which the word "sound" is repeated three times and other dimensions of sound are embedded (thereby account of Leroy 1967, 236 will be corrected, made more precise and broadened). Here the issue is about analysis and understanding some parts of Simonides poem. In this context, the different understandings of the interlocutors of Greek word $\chi \alpha \lambda \varepsilon \pi$ óv (341b) make an occasion which Socrates proposes a discussion about sound with special connotation and meaning.

With regard to this issue that the main interpretations and discussions of interlocutors return to the meaning of the word $\chi \alpha \lambda \varepsilon \pi$ òv, Socrates suggests it would be better we ask the meaning of the word from Prodicus of Cos for he lives in the city where Simonides lives and they both speak the same phone. What can be the equivalent of phone? It seems that when a phone is spoken by the inhabitant of a geographical region, we are justified to call this phone dialect of that region and people. Accordingly, with regard to the part of the area called Ionia where these two individuals live, we can ask 
about the meaning of $\chi \alpha \lambda \varepsilon \pi$ ó $v$, which is in Ionian alphabet, from a living individual who is present at the discussion and speaks with the Ionian dialect (341b).

This suggestion makes us curious about the speaking language of the interlocutors of Plato dialogues in general, especially when the main characters come from different "regions", for dialect is a topical or place-related category (W. S. Allen 1968, vii, viii). But here we do not want consider this general question but only Protagoras. Here according to the explicit wordings of Plato, we can take living in a specific common region as the main criterion of a dialect, and since both Simonides and Prodicus live in a common region, so they speak a common dialect that is "Dorian". As such, we can infer that Protagoras dialect is "eastern Ionic", Prodicus "Dorian", Socrates "Attic", Hippias "Aeolic", and Pittacus "Lesbian" (341c) which all belong to the East Greek / Old Hellenic division (Buck 1928, 8). Thus, analogous with the plurality of poleis, we are faced with a plethora of dialects (Quintela 2009, 253). Then it is the question, is the dialogue performed through different dialects? If not, what is the common speaking language or dialect? What are the relations of dialects with each other? Is it Attic or there is another common agreed / koine one? Are there any differences between speaking and writing dialect? There are different answers to these questions but what can be inferred from this dialogue, is as follows: all these dialects come under East Greek and have interrelations, intermixing and "relative" mutual intelligibility (otherwise there was no need to seek for the meaning of $\chi \alpha \lambda \varepsilon \pi \mathrm{o} v$ in Ionic dialect), "for purposes of simple communication, and most of them in the case of more extended discourse" (Buck 1906, 108). But with regard to the association of a specific literal genre with a specific dialect (Smyth 2010,4), it is "literal Attic" that is the common (koine) and standard speaking and writing language of this philosophical dialogue (Bonner 1909,361).

Let's return to the dialogue. It can be said that there is a man called Pittacus and in response to him Simonides' poem should be understood. His dialect is different / foreign for Simonides and it seems that in his response, he uses two dialects (346d). Accordingly, Simonides knows two dialects, one his own native region that is central Ionia and the other one is the special dialect of Pittacus who comes from Mytilene in Lesbos (346e). And this shows a kind of dialect realism, a conscious and friendly attitude from Simonides in order to communicate with Pittacus on his own native dialect that according to Beresford translation even approaches to the Mytilenian colloquy:

"I gonna give my praise

and love to any man" (Adam Beresford 2013, 57). 
As a result, in this part of dialogue set we have met five main large geographical ethnic regions in which their inhabitants have their own dialect, and this is a new dimension we are reading for the first time. Of course, when in dialogue different dialect speakers want to speak and dialogue on a difficult and intellectual issue, with regard to the time of dialogue and the currency of Attic dialect, it is natural and predictable that the "shared common dialect" is Attic, otherwise meaningful and understandable dialogue is impossible.

\section{Human and Musical phone}

Now, we reach to the set in which the word voice is used five times $(347 \mathrm{c}-347 \mathrm{e})$ in relation to human beings and a specific pneumatic musical instrument. Here Platonic Socrates use the same word phone for two different but analogous entities that are based on pneuma: human being and flute - in the context of classical Greek, flute as a musical instrument is opposite to the other instruments, especially Kithara.

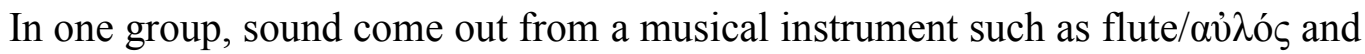
common ordinary people like the sound that comes to their ears from outside of them as the other / $\dot{\alpha} \lambda \lambda o \tau \rho i ́ \alpha v ~ \varphi \omega v \eta ́ v \quad$ (347c). It seems that on the basis of this very reason, Plato shares in the deep-seated aversion to the Aulos in ancient Greek. In contrast, there is another group of cultured individuals who in their gatherings hear the voice that originates from within and in a word belongs to themselves / $\tau \tilde{\eta} \varsigma \alpha \dot{\tau} \tilde{\omega} v \varphi \omega v \tilde{\eta} \varsigma$. Here this voice is a special sound that is cultured in a specific way and needs no outer external musical instrument. This "cultured / Paideia" voice in distinction and beyond the mere correct pronunciation of sounds in schools (we have read in Protagoras' logos narrative), has a deep and emphasized relation with the "inner" of human beings - the crucial word self $\alpha \tilde{\tau} \tilde{\omega} v$ is repeated three times together with phone $(347 \mathrm{~d})$.

According to this set, the origin of sound can be human and a pneumatic musical instrument. But when we use it in relation to human beings, we are not concerned with ordinary people but with particular human beings who are cultured individuals. Thus, according to a dichotomy of human beings, there are two kinds of sounds. One class of people has the inner and internal motor for producing voice who are in opposition with those who as a class does not have or shaped their inner being and should rely on the outer and external one that comes from a pneumatic musical instrument that is notorious.

Thereby, we can infer that the qualitative or cultured (paideia) sound has relation 
with the formation of a particular inner independent core in human being. And this kind of voice is both the main subject of logos and object of real hearing /

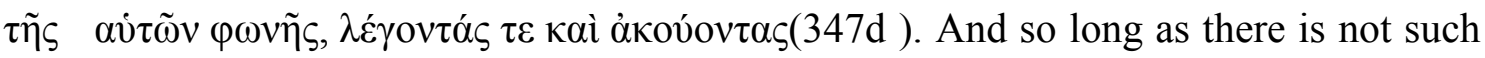
an inner identity, human beings depend on something other than themselves out there that has different examples and extensions. According to this normative suggestion, Platonic Socrates recommends that we should shape such an inner being and according to its inner voice dialogue with each other.

Phone as Metaphor

At the end of dialogue, we face another aspect of sound in distinction from the beginning that was about the real and alive voice of a man. The dialogue begins with a masculine voice and ends with a feminine voice. In this position, she can be personalized as a living entity (361a), who as the third party can make questions of Socrates and Protagoras about the content and result of their dialogue and discussions. Metaphorically, the written dialogue as a living entity has voice, and here that we have reached the last part as the conclusion, it can be vocalized and make a general question about the whole dialogue. Can it be the voice of Plato the writer of dialogue?

\section{Conclusion}

In Protagoras, Plato introduces and mentions some aspects of phone in very short and brief phrases and sentences that we collected here in some reasonable sets with specific titles. Though, these hints are multiple and short, as a reader we can provide common justifiable thread in order to link them together. In this relation, I want to suggest that in the dialogue as a whole, Plato considers phone in relation to both human and nonhuman entities in both real and metaphorical aspects as a sound that originates from an entity and the ears of us as normal listeners hear it: phone - listening. This sound can have characteristics such as being high/low; loud/quiet; magic; enchanting; cultured; and having mood. Therefore, each human being has a "phonic identity" that is a combination of both qualitative and quantitative aspects. Moreover, phone or sound can be considered as constitutive of other units such as word, speech, writing and functions as their arche. If we consider the construct of word, speech and script at their initial formation and articulation, we can see that phone in conscious or unconscious ways forms the building 
block of them. And when a common and shared voice covers a common region and its inhabitant it can be considered as "dialect" of the region.

Mostafa Younesie

Independent Scholar

\section{Bibliography}

Beresford, Adam. Plato: Protagoras and Meno. Penguin Books 2005.

Bonner, Robert J. The Mutual Intelligibility of Greek Dialects. The Classical Journal, Vol. 4, No. 8 (Jun., 1909), pp. 356-363.

Buck, Carl Darling. The General Linguistic Conditions in Ancient Italy and Greece. The Classical Journal, Vol. 1, No. 4 (Mar., 1906), pp. 99-110.

García Quintela, Marco V. The Phonological Politics of Plato and the Myth of Protagoras. Metis N.S. 7 2009. 247-276.

Gera, Deborah Levine. Ancient Greek ideas on speech, language, and civilization. Oxford University Press, 2003. https://doi.org/10.1093/acprof:oso/9780199256167.003.0002

Lamb, W.R.M. Plato, Plato: Laches, Protagoras, Meno, Euthydemus. Harvard University Press, 1924.

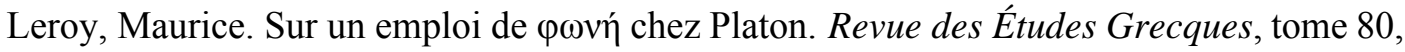
1967. pp. 234-241. https://doi.org/10.3406/reg.1967.3944

McKinnon, James. The Temple, the Church Fathers and Early Western Chant. Routledge 1998.

Mickey, K. Dialect Consciousness and Literary Language: An Example from Ancient Greek, Transactions of Philological Society, Volume 79, Issue 1, November 1981, Pages 3566. https://doi.org/10.1111/j.1467-968x.1981.tb01186.x

Smyth, H. W. Greek Grammar. Benediction Classics 2010.

Tuplin, Christopher. Science and Mathematics in Ancient Greek Culture. Oxford 2002. https:// doi.org/10.1093/acprof:oso/9780198152484.001.0001 